\title{
The Effects of Various Treatments of Paddy Rice on the Aneurin and Nicotinic Acid Content of the Milled Grain
}

\author{
By J. DONE \\ Human Nutrition Research Unit, Medical Research Council Laboratories, \\ Holly Hill, Hampstead, London, N.W. 3
}

(Received 28 September 1949)

The first stage in the preparation of rice for food is the threshing of the harvested crop to yield paddy rice. This consists of the rice berry (or grain) enclosed in a rough, fibrous and silicious husk. Further preparation consists of hulling to remove this husk, followed by milling which removes the outer bran layer of the berry.

For some time before beriberi was shown to result from a deficiency of vitamin $B_{1}$ it was known that the disease could be prevented and cured by a diet of parboiled rice. Aykroyd (1932) showed that a sample of milled parboiled rice contained a considerable amount of vitamin $B_{1}$, although most of the bran had been removed by milling, whereas milled grain that had not been treated by the process was deficient in the vitamin. Platt (1939) stressed the importance of parboiling as a method of conserving the vitamin $B_{1}$ of rice.

Parboiling originated centuries ago in India, and several procedures are now employed in different parts of the world. They involve soaking the paddy in water at various temperatures. The grain may also be steamed for a short period after the excess water has been drained off. The paddy is finally dried in the sun or by artificial means.

Jones, Zeleny \& Taylor (I946) investigated the effect of twelve different treatments on the aneurin content of the milled grain. Highly milled samples after treatment contained roughly four to five times as much aneurin as untreated samples milled to the same degree. A considerable range of treatments in which such conditions as soaking and steaming were varied has been studied by Kik (1946). The treated grain after milling has a higher aneurin content than untreated grain similarly milled. Kik \& Williams (1945) have also shown that the nicotinic acid content of milled rice is more than doubled by parboiling. Hinton (1948-9) recently investigated the distribution of aneurin in the rice grain, and obtained direct evidence that during a parboiling process the vitamin moves from the germ and the pericarp-aleurone region into the endosperm (Hinton, 1948).

The characteristics of parboiled rice which appear to have influenced populations that adopted the process include facilitation of hulling, reduction of breakage during hulling and milling and retention of shape by the cooked grain. The methods have been developed empirically. Many of them cause marked changes in the colour, odour and taste of the milled grain so that the product is only acceptable to limited sections of the consumers. It has been shown, by the workers referred to above, that 
parboiling by a considerable number of different methods results in increases of the same order of magnitude in the aneurin content of the milled grain. The present work was undertaken to determine the conditions of treatment essential for satisfactory redistribution of both aneurin and nicotinic acid, and also to examine the possibilities of achieving this without marked changes in the colour, odour and flavour of the grain.

\section{METHODS}

\section{Estimation of aneurin}

Adaptations of the fluorimetric method described by the Vitamin B Sub-committee of the Accessory Food Factors Committee (1943) were used.

Extraction of the finely powdered grain overnight in $2 \%(w / v) ~ H C l$ at room temperature was satisfactory for untreated samples. Inconsistent results were obtained, however, when this procedure was applied to parboiled samples. The results

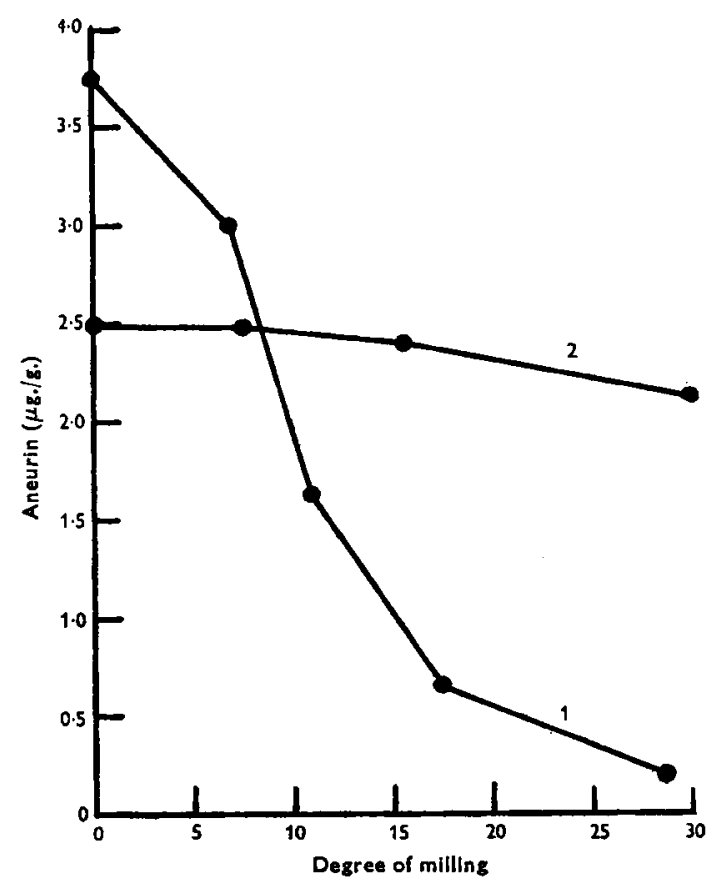

Fig. I. Change in the aneurin content of milled rice after a Trinidad parboiling process. Curve 1, untreated; curve 2, parboiled.

shown in Figs. $I$ and 2 were obtained after extraction by the following method: samples were heated in the acid for $10 \mathrm{~min}$. at $60^{\circ}$, cooled, ground with powdered glass and

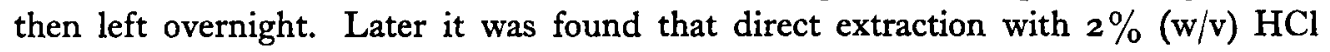
was satisfactory if the sample was first homogenized (Potter \& Elvehjem, 1936). The results given in Table 3 were obtained in this way.

However, in most cases the extraction was carried out by the following method, based on the procedure of Hennessy (I947). 
The sample (1-2 g.) was heated in $20 \mathrm{ml}$. $\mathrm{O} \cdot \mathrm{IN}$ sulphuric acid for $10 \mathrm{~min}$. in a waterbath at $100^{\circ}$, cooled and the $\mathrm{pH}$ adjusted to 4.5 with $30 \%$ sodium-acetate solution; $25 \mathrm{mg}$. of a takadiastase preparation (Parke, Davis \& Co.) were added for every I $\mathrm{g}$. of sample taken, followed by 5 drops of toluene and the mixture was kept in a waterbath at $40^{\circ}$ for $14^{-20} \mathrm{hr}$. It was then cooled, made up to $50 \mathrm{ml}$. and filtered through a Whatman no. I paper, the first 5-10 ml. of filtrate being discarded.

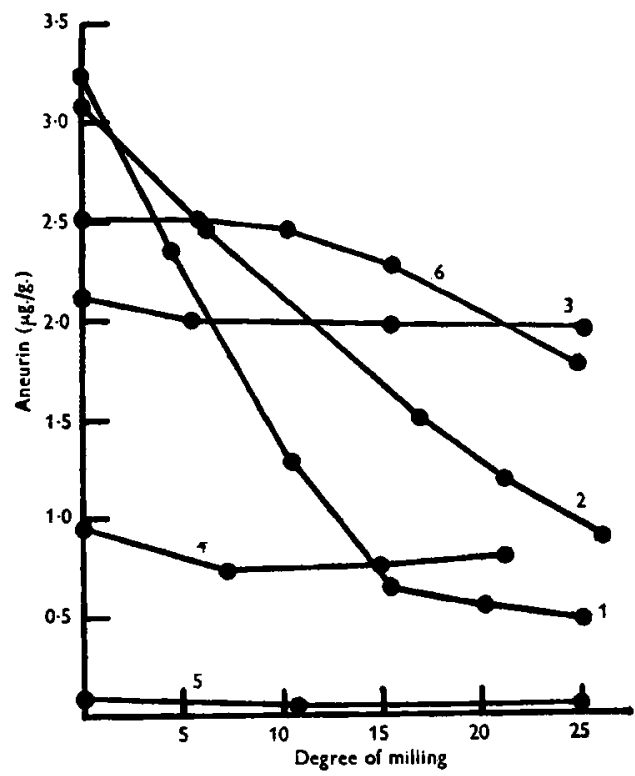

Fig. 2. Effect of soaking in water on the aneurin content of milled rice grain. Temperature $74^{\circ}$ after the first $30 \mathrm{~min}$. Curve I, untreated; curve 2, soaked $3 \mathrm{hr}$.; curve 3 , soaked $5 \frac{1}{2} \mathrm{hr}$.; curve 4 , soaked $24 \mathrm{hr}$.; curve 5, soaked $48 \mathrm{hr}$.; curve 6 , soaked $3 \mathrm{hr}$., steamed $20 \mathrm{~min}$. at $\mathrm{r} 5 \mathrm{lb}$./sq.in. pressure.

Although the blank was thereby reduced considerably, no appreciable difference in the result was observed when the extract was washed with isobutanol. The measurement of the fluorescence resulting from 0.05-0.15 $\mu \mathrm{g}$. of aneurin was made possible by the use of a sensitive fluorimeter, designed by Dr R. A. Webb of this laboratory (unpublished).

The technique for the oxidation stage, as described by Bouman (1948), was found to give good agreement of replicates, and it was used in all the analyses except those reported in Figs. I and 2. Six $2 \mathrm{ml}$. portions of the extract were taken. The first two were blanks and were treated only with sodium hydroxide. The second two were oxidized with potassium ferricyanide in the manner described by Bouman. Aneurin solution (0.1 $\mu \mathrm{g}$. in $0.1 \mathrm{ml}$.) was added to each of the third pair before oxidation. The standard fluorescence was the difference between the third and second pair of tubes.

\section{Estimation of nicotinic acid}

A colorimetric method was used, based on the reaction of nicotinic acid with cyanogen bromide and aniline (Swaminathan, 1938, 1942). Attempts to apply the technique of Dann \& Handler (I94I) for the clarification of extracts were not success- 
ful. The following procedure was adopted after experimental work on the different stages of the method.

\section{Reagents}

Hydrochloric acid A.R.

Hydrochloric acid A.R.

O. I N

Sodium hydroxide A.R.

Conc.

Trichloroacetic acid

$60 \%(w / v)$

Potassium permanganate A.R.

$55 \%(\mathrm{w} / \mathrm{v})$

Cyanogen-bromide solution

$4 \%(w / v)$

Prepared daily by decolorizing ice-cold saturated aqueous bromine solution with $10 \%(\mathrm{w} / \mathrm{v})$ sodium-cyanide solution. It was kept in ice-water

$0.1 \%$ ethanolic aniline solution $(v / v)$

Redistilled aniline dissolved in pure alcohol

Disodium phosphate A.R.

$\mathrm{Na}_{2} \mathrm{HPO}_{4}$. I $2 \mathrm{H}_{2} \mathrm{O}$

Extraction. From 0.5 to $1 \cdot 5 \mathrm{~g}$. of finely powdered (80 mesh) rice was mixed with $25 \mathrm{ml}$. of $0 . \mathrm{IN}-\mathrm{HCl}$. The mixture was shaken mechanically for $\mathrm{I}-2 \mathrm{hr}$. and then allowed to stand overnight at room temperature. After centrifugation, $20 \mathrm{ml}$. of the supernatant fluid were pipetted off.

Precipitation of protein. For this purpose $2 \mathrm{ml}$. of $55 \%$ trichloroacetic acid were added. After IO-I $5 \mathrm{~min}$. the protein precipitate was removed by centrifugation, and $20 \mathrm{ml}$. of the supernatant solution were transferred to a $6 \times \mathrm{I}$ in. tube.

Hydrolysis. Conc. hydrochloric acid $(5 \mathrm{ml}$.) was then added and the tube immersed in boiling water for $40 \mathrm{~min}$. and finally cooled.

Permanganate oxidation. To the solution $4 \mathrm{ml}$. of $60 \%$ sodium hydroxide were added. After cooling to $40-50^{\circ}$ the mixture was decolorized by the addition of $4 \%$ potassium permanganate. Usually three to five drops only were required.

Next $0.3 \mathrm{~g}$. of disodium phosphate was added and the mixture adjusted to $\mathrm{pH} 6 \cdot 6-6 \cdot 8$ with sodium hydroxide. The mixture was then transferred to a $50 \mathrm{ml}$. graduated flask containing $20 \mathrm{ml}$. of a $0.1 \%$ ethanolic solution of aniline, allowed to stand $10-15 \mathrm{~min}$. after making up to volume, and finally centrifuged.

Colour development. Portions $(5 \mathrm{ml}$.) of the supernatant fluid were added to each of six $25 \mathrm{ml}$. glass-stoppered cylinders. The first pair were the 'blank' tubes, the second pair the 'test' tubes, and to each of the third pair $2.75 \mu \mathrm{g}$. of nicotinic acid were added as solution from a micro-pipette. Then $2 \mathrm{ml}$. water were added to the first pair of tubes, $2 \mathrm{ml}$. of cyanogen-bromide solution were added to each of the other tubes and the optical density was measured when the colour developed had reached a maximum, usually after ro-12 min. The readings were made on a Coleman Junior Spectrophotometer set at $440 \mathrm{~m} \mu$. and $100 \%$ transmission, with distilled water in the cuvette.

'Reagent blank.' A 'reagent blank' was prepared by submitting $20 \mathrm{ml}$. of the $0.1 \mathrm{~N}-\mathrm{HCl}$ to the same treatment as the $20 \mathrm{ml}$. of an extract, and duplicate $5 \mathrm{ml}$. portions of the resulting ethanolic solution were treated with cyanogen bromide. The 
optical density of the mixture was determined after the interval corresponding to the maximum colour development in the extracts.

\section{Calculation.}

$$
\frac{T-B}{S-T} \times \frac{37 \cdot 8}{W}=\mu \mathrm{g} . \mathrm{g} .
$$

where $T=$ mean optical density given by the 'tests', $B=$ mean optical density given by the 'blanks' plus the optical density of the 'reagent blank', $S=$ mean optical density given by the tubes to which $2.75 \mu \mathrm{g}$. of nicotinic acid were added, and $W=$ weight of sample used (g.).

The samples for which the results given in curve 3 , Fig. $3 b$ were obtained have been analysed in another laboratory by the microbiological method with Lactobacillus arabinosus. Table I gives the values obtained by the two methods.

\section{Table I. Chemical and microbiological estimations of the nicotinic acid content of four samples of rice}

$\begin{array}{ccc}\text { Sample no. } & \begin{array}{c}\text { Chemical } \\ \text { method } \\ (\mu \mathrm{g} \cdot / \mathrm{g} .)\end{array} & \begin{array}{c}\text { Microbiological } \\ \text { method } \\ (\mu \mathrm{g} \cdot / \mathrm{g} .)\end{array} \\ \text { I } & 60 \cdot 0 & 63 \\ 2 & 45 \cdot 5 & 44 \\ 3 & 38 \cdot 5 & 34 \\ 4 & 33 \cdot 2 & 33\end{array}$

\section{Laboratory preparation of milled rice from paddy}

Hulling. (Preparation of 'whole' rice, 'brown' rice.) Hulls were removed from a small sample (20-50 g.) of paddy by careful pounding in a large mortar. The sample was. then heaped at one side of the mortar, stirred, and a jet of air directed on to it from above so that the separated hulls collected at the opposite side of the mortar. Larger samples were hulled mechanically by means of a machine modelled on the principle of the commercial 'huller' and the separated hulls were removed by aspiration.

After these treatments whole and unhulled rice were separated by hand.

Milling. A small mill was designed to mill uniformly with very little loss of germ at early stages of milling. A grinding wheel (4 in. diameter) was mounted so that it could be rotated mechanically in a horizontal plane inside a vertical metal cylinder. Inside this cylinder a vertical metal plate was arranged so that when a sample of rice was placed on the wheel it piled up at one side of the plate, which thus acted as a baffle. In this way the rough surface of the wheel was made to pass under the heap of grain and at the same time the individual grains were kept in constant motion. Material removed from the surface of the grain passed down the narrow gap between the edge of the wheel and the cylinder. The amount of material removed was controlled by finding the loss of weight of the grain. The percentage loss of weight was called the 'percentage bran yield' or the 'degree of milling'. Samples were analysed after various degrees of milling. 
RESULTS

\section{The effect of a Trinidad parboiling treatment on the aneurin content of the milled grain}

Samples of the same paddy, before and after parboiling, were obtained from Trinidad.

The treated paddy had been soaked in water overnight, the greater part of the water drained off, and the container heated until steam from the residual water had caused the hulls to open slightly. The paddy was finally dried. Both samples were hulled and milled by the laboratory method described. At $12-15 \%$ bran yield the samples had an appearance similar to that of highly milled commercial rice. Samples from stages up to a point where nearly one-third of the grain by weight had been removed from the surface were analysed, however, so that the effect of the process on the distribution of aneurin in the grain could be ascertained. The results are given in Fig. I.

As can be seen, treatment caused a $33 \%$ loss of aneurin and the distribution of this substance inside the grain, as shown by analysis of the milled grain, had been changed. After the treatment the aneurin content of the milled grain was almost constant, i.e. it was almost independent of the quantity and nature of the material removed by the mill. Removal of $25 \%$ by weight of the berry caused the aneurin content of the milled grain to decrease 10\% in parboiled rice, as compared with a $90 \%$ decrease in untreated rice.

\section{Redistribution of aneurin and nicotinic acid in the grain caused by soaking}

Exp. I. A I kg. sample of paddy rice from British Guiana was placed in 1.25 l. of tap water at $80^{\circ}$ contained in a beaker. The beaker was covered and kept in a waterbath at $80^{\circ}$ so that heating could be maintained for $48 \mathrm{hr}$. Immediately after the paddy was added, the temperature inside the beaker fell to $60^{\circ}$. The contents of the beaker were stirred at intervals and the temperature recorded. After $30 \mathrm{~min}$. it had risen to $74^{\circ}$ and it was found not to change by more than $\pm I^{\circ}$ thereafter. Samples of paddy were removed for analysis after $3,5 \frac{1}{2}, 24$ and $48 \mathrm{hr}$. Part of the $3 \mathrm{hr}$. sample was steamed for $20 \mathrm{~min}$. at $15 \mathrm{lb}$./sq.in. pressure. The treated samples were spread on trays and allowed to remain at room temperature for 3 days. It had been found that samples dried in this way returned to approximately their original weight. Analyses were also carried out on samples of the untreated grain. The results are shown in Fig. 2.

After soaking for $5 \frac{1}{2} \mathrm{hr} ., 35 \%$ of the aneurin was lost, but the aneurin content of the milled grain was almost constant (Fig. 2, curve 3). Continued treatment did not alter the type of curve obtained but, after soaking for $24 \mathrm{hr}$., $7 \mathrm{r} \%$ of the aneurin had been lost and, after $48 \mathrm{hr}$., $97 \%$.

The highest aneurin content of the milled grain was obtained by soaking for $3 \mathrm{hr}$. followed by steaming (Fig. 2, curve 6). This treatment was similar to one of the treatments studied by Jones et al. (1946). Fig. 2 indicates that soaking for between 3 and $5 \frac{1}{2}$ hr. may have a similar effect.

Exp. 2. The procedure was similar to that of Exp. I, but the water-bath was main- 
tained at $97-98^{\circ}$. The temperature inside the beaker rose to $87^{\circ}$ in $15 \mathrm{~min}$. and was found subsequently not to change by more than $\pm I^{\circ}$. Samples of the paddy were removed after $23 \mathrm{~min}$., I, $1 \frac{1}{2}$ and $2 \mathrm{hr}$. They were dried and milled to various degrees in the manner already described. Results are shown in Fig. 3 .

Fig. $3 a$ shows that redistribution of aneurin had occurred in a manner similar to that in Exp. x. However, the increased temperature had a marked influence on the rate of the changes. Curve 3, Fig. 2, representing the condition after $5 \frac{1}{2} \mathrm{hr}$. at $74^{\circ}$ is similar to curve 4 , Fig. 3 , representing the condition after $I_{2}^{1} \mathrm{hr}$. at $87^{\circ}$.

There was no appreciable loss of nicotinic acid as a result of the treatment, as indicated by analysis of the unmilled grain (Fig. 3 b). If the grain is soaked for $\mathrm{I} \mathrm{hr.}$ and milled, it would seem from curve 3 , Fig. $3 a$, that a redistribution of aneurin takes place, resulting in a marked increase in the aneurin content of the endosperm. However, with nicotinic acid a corresponding increase required $2 \mathrm{hr}$. soaking (curve 5 , Fig. $3^{b}$ ).

\section{Effect of various treatments on the aneurin and nicotinic acid content of the milled grain}

Samples (250 g.) of paddy (variety 'Fortuna') were soaked in 21 . of tap water for treatments $\mathrm{I}-7$ (Table 2). The grain was kept in suspension by means of a mechanical stirrer.

The effect of increased hydraulic pressure, during soaking for $2 \mathrm{hr}$. at $80^{\circ}$, was also tested. The paddy (roo g.) and $15 \circ \mathrm{ml}$. water were placed in each of two $500 \mathrm{ml}$. conical flasks, kept in a water-bath. The control flask was closed by a glass bubble (treatment 8, Table 2). The other flask was connected to a nitrogen cylinder so that the pressure in the space above the water could be increased to $40 \mathrm{lb}$./sq.in. (treatment

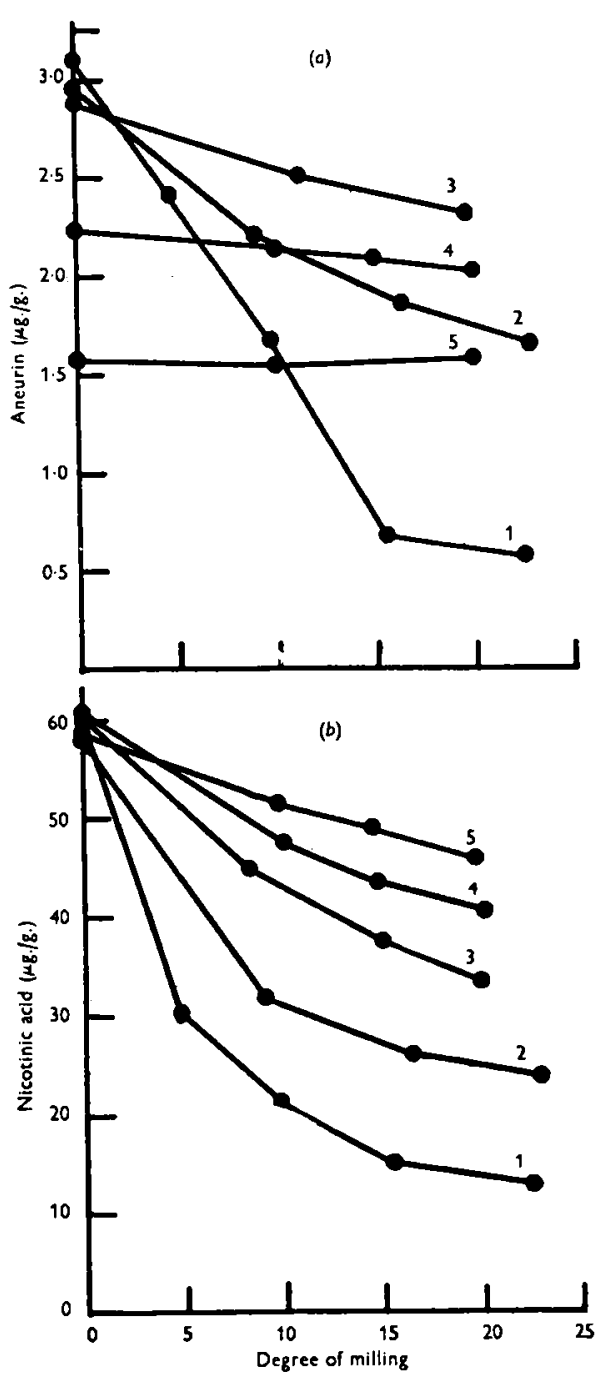

Fig. 3. Effect of soaking in water on $(a)$ the aneurin, and $(b)$ the nicotinic acid content of milled grain. Temperature $87^{\circ}$ after the first I 5 min. Curve I, untreated; curve 2, soaked 23 min.; curve 3 , soaked I hr.; curve 4, soaked I $\frac{1}{2}$ hr.; curve 5 , soaked 2 hr.

9, Table 2). All treatments caused some loss of aneurin: $30 \mathrm{~min}$. in water at $100^{\circ}$ and $30 \mathrm{~min}$. in steam at $100^{\circ}$ after soaking overnight in water at $100^{\circ}$ produced the least loss. 
Table 2. Effects of various treatments on the aneurin and nicotinic acid content of the rice grain

(For treatments nos. I-7 $250 \mathrm{~g}$. samples of paddy, variety 'Fortuna' were soaked in 21 . water, and for treatments nos. 8 and 9, I00 g. samples in $150 \mathrm{ml}$. water were used; see text, p. 34I.)

\begin{tabular}{|c|c|c|c|c|c|}
\hline \multirow{2}{*}{\multicolumn{2}{|c|}{ Treatment }} & \multicolumn{2}{|c|}{ Aneurin } & \multicolumn{2}{|c|}{ Nicotinic acid } \\
\hline & & \multirow{2}{*}{ 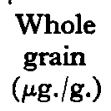 } & \multirow{2}{*}{$\begin{array}{l}15 \% \\
\text { milled } \\
(\mu \mathrm{g} . / \mathrm{g} .)\end{array}$} & \multirow{2}{*}{$\begin{array}{l}\text { Whole } \\
\text { grain } \\
(\mu \mathrm{g} . / \mathrm{g} .)\end{array}$} & \multirow{2}{*}{$\begin{array}{c}\text { 15\% } \\
\text { milled } \\
(\mu \mathrm{g} . / \mathrm{g} .)\end{array}$} \\
\hline No. & Procedure & & & & \\
\hline $\mathbf{I}$ & $\begin{array}{l}\text { Untreated } \\
30 \mathrm{~min} \text {. at } 100^{\circ}\end{array}$ & $\begin{array}{l}3.21 \\
2.58\end{array}$ & $\begin{array}{l}0.75 \\
2 \cdot 20\end{array}$ & $\begin{array}{l}42 \cdot 2 \\
40 \cdot 0\end{array}$ & $\begin{array}{l}7 \cdot 15 \\
26 \cdot 6\end{array}$ \\
\hline 2 & $2 \downarrow \mathrm{hr}$. at $90^{\circ}$ & 1.83 & 1.85 & $44 \cdot 0$ & 30.4 \\
\hline 3 & $4 \mathrm{hr}$. at $80^{\circ}$ & $2 \cdot 20$ & $2 \cdot 04$ & $42 \cdot 8$ & $29 \cdot 3$ \\
\hline 4 & $8 \mathrm{hr}$. at $70^{\circ}$ & 2.00 & $1 \cdot 02$ & $37 \cdot 8$ & $27 \cdot 5$ \\
\hline 5 & $16 \mathrm{hr}$ at $60^{\circ}$ & $2 \cdot 25$ & I.OI & $37 \cdot 0$ & 29.8 \\
\hline 6 & $\begin{array}{l}\text { At room temp. overnight, then } \\
\text { boiled } 30 \mathrm{~min} \text {. }\end{array}$ & $2 \cdot 39$ & $2 \cdot 08$ & $43 \cdot 0$ & $32 \cdot 0$ \\
\hline 7 & $\begin{array}{l}\text { At room temp. overnight, then } \\
\text { steamed at } 100^{\circ} \text { for } 30 \mathrm{~min} \text {. }\end{array}$ & $2 \cdot 50$ & $2 \cdot 14$ & $43 \cdot 2$ & $26 \cdot 0$ \\
\hline 8 & $2 \mathrm{hr}$. in water-bath at $80^{\circ}$ & $2 \cdot 48$ & $2 \cdot 26$ & $42 \cdot 8$ & $23 \cdot 4$ \\
\hline 9 & $\begin{array}{l}2 \mathrm{hr} \text {. in water-bath at } 80^{\circ} \text { under } \\
\text { nitrogen at } 40 \mathrm{lb} . / \mathrm{sq} . \text { in. }\end{array}$ & $2 \cdot 52$ & $2 \cdot 12$ & 43.5 & $22 \cdot 1$ \\
\hline
\end{tabular}

The effect of treatment on redistribution of aneurin can be seen by comparing the figures for whole grain (Table 2) with those for $15 \%$ milled. The treatments referred to in the last paragraph, which produced the least loss of aneurin, also yielded milled grain with the highest aneurin content; $2 \frac{1}{4} \mathrm{hr}$. at $90^{\circ}$ gave a very uniform distribution of aneurin, but marked loss occurred. Treatment for $8 \mathrm{hr}$. at $70^{\circ}$ or $\mathrm{I} 6 \mathrm{hr}$. at $60^{\circ}$ did not have so great an effect on redistribution as the shorter periods at higher temperatures.

Treatments at $80-100^{\circ}$ appeared to have the same general effects on the aneurin in the grain, and temperature conditioned the rate, rather than the nature, of the changes. However, of the milled samples with a similar aneurin content, the one soaked $2 \mathrm{hr}$. at $80^{\circ}$ had only a slight yellow colour, whereas those treated at higher temperatures were much more coloured. In practice precautions would be necessary, if treatment at $100^{\circ}$ was employed, to ensure the maximum retention of aneurin, because of the rapidity of the changes at this temperature.

No thermal destruction of nicotinic acid would be expected under the experimental conditions. With two exceptions the nicotinic acid content of the whole grain remained approximately constant, irrespective of temperature or duration of soaking. If these two low values were not due to experimental error it may be concluded that prolonged soaking at elevated temperatures leads to some loss, perhaps by leaching.

Treatments I-5 (Table 2) had a similar effect on the nicotinic acid content of the milled grain, all the figures being within the range $26 \cdot 5-30 \cdot 5 \mu$ g./g., i.e. approx. $70 \%$ of the nicotinic acid content of the untreated whole grain. Soaking for $2 \mathrm{hr}$. at $80^{\circ}$ yielded a milled rice with only $57.5 \%$ of the nicotinic acid content of the untreated whole grain, but the corresponding figure for aneurin was approximately $70 \%$.

The redistribution of nicotinic acid appeared to be slower than that of aneurin at 
$87^{\circ}$ also (Fig. 3), but treatments 4 and 5 , Table 2, at 70 and $60^{\circ}$ respectively, caused as much movement of nicotinic acid as any other treatment, though there was only a small redistribution of aneurin. The increased hydraulic pressure (treatment 9) had no appreciable effect on vitamin content.

\section{Aneurin and nicotinic acid content of the germ}

A $500 \mathrm{~g}$. sample of 'Fortuna' rice was maintained at $80-8 \mathrm{r}^{\circ}$ in $500 \mathrm{ml}$. distilled water for $2 \mathrm{hr}$. The paddy was dried and samples were milled to $10 \%$ and to $15 \%$ bran yield. The germ was removed from part of each sample by dissection and the results of aneurin estimations are given in Table 3 .

Table 3. Contribution of the aneurin in the germ to total aneurin in untreated and parboiled rice before and after milling

(For treatments nos. 2-4 portions of a $500 \mathrm{~g}$. sample of 'Fortuna' rice were maintained for $2 \mathrm{hr}$. at $80-81^{\circ}$ in $500 \mathrm{ml}$. distilled water.)

\begin{tabular}{|c|c|c|c|c|c|c|}
\hline & & & & & Germ & \\
\hline & & & When & & & arin \\
\hline & Treatment & T & germ & Percentage & & Pon \\
\hline No. & Procedure & $(\mu \mathrm{g} . / \mathrm{g})$. & $(\mu \mathrm{g} . / \mathrm{g})$. & weight & $\mu \mathrm{g} . / \mathrm{g}$ & of total \\
\hline $\mathbf{I}$ & Untreated & $3 \cdot 22$ & $2 \cdot 17$ & I.9 & $56 \cdot 6$ & $35 \cdot I$ \\
\hline $\mathbf{2}$ & Treated. Not milled & $2 \cdot 90$ & $2 \cdot 46$ & $1 \cdot 7$ & $26 \cdot 0$ & 14.0 \\
\hline 3 & Treated. Milled 10\% & $2 \cdot 51$ & $2 \cdot 20$ & 1.0 & $26 \cdot 6$ & $10 \cdot 6$ \\
\hline 4 & Treated. Milled I5\% & $2 \cdot 29$ & $2 \cdot 10$ & 0.76 & $29 \cdot 0$ & $9 \cdot 7$ \\
\hline
\end{tabular}

A sample of the untreated rice was milled to $15 \%$ bran yield and all residual germ removed. The material so obtained consisted almost entirely of endosperm and closely resembled commercial highly milled rice. It contained $0.4 \mu \mathrm{g}$./g. of aneurin.

The treatment reduced the aneurin content of the germ to less than half its initial value, and the contribution of the germ to the total aneurin fell from 35 to $14 \%$. The treated rice, $15 \%$ milled, contained $2.29 \mu \mathrm{g}$. $/ \mathrm{g}$. aneurin and only $10 \%$ of this was due to the germ. When the germ was removed from it, the rice contained $2 \cdot 10 \mu \mathrm{g}$. $/ \mathrm{g}$., and consisted almost entirely of endosperm. It can be seen, therefore, that the germ of the treated milled rice makes only an insignificant contribution to the final aneurin content of the prepared rice, and the observed value is mainly due to actual movement of aneurin from the germ and bran layer into the endosperm.

The germ of the rice for which the results given in Fig. $3^{b}$ were obtained had a nicotinic-acid content of $50 \cdot 3 \mu \mathrm{g}$. $/ \mathrm{g}$., and the remainder of the grain one of $6 \mathrm{I} \cdot 0 \mu \mathrm{g}$. $/ \mathrm{g}$. However, Fig. $3^{b}$ shows that $50 \%$ of the nicotinic acid in the untreated grain was in the material removed by milling to $5 \%$ bran yield, and that after treatment for $2 \mathrm{hr}$. this region contained only about $6 \%$ of the total nicotinic acid. The conservation of nicotinic acid by the process is, therefore, due to movement of this substance towards the endosperm from the outer region (pericarp, aleurone layer and outer endosperm). 


\section{DISCUSSION}

The parboiling processes employed in various parts of the world have been developed empirically, mainly on the basis of the milling and cooking qualities of the processed grain. It is well known now that many of the processes increase the aneurin content of the milled grain, and several have been shown to increase the nicotinic acid content. Little information is available on the significance of conditions of treatment in relation to the vitamin content of the milled grain. The results reported here have a number of points of practical interest.

All treated samples showed some loss of aneurin, the magnitude of the loss was a combined effect of temperature and time of treatment. Fortunately, the rate of destruction was not high enough to vitiate attempts to raise the aneurin content of the milled grain. Redistribution occurred at such a rate that, although total aneurin decreased, it was possible to select a treatment such that, after milling, the grain contained more aneurin and nicotinic acid than untreated grain similarly milled.

Both the absorption of water and the application of heat to the moist grain seemed to be necessary, but it is clear from the results that soaking before heating is not essential. Simultaneous soaking and heating is effective.

Redistribution seemed to follow a similar course over the temperature range $74-100^{\circ}$. Although treatments at different temperatures can produce milled grain differing little in vitamin content, the more elevated temperatures gave products that were discoloured as compared with untreated samples. However, soaking for $2 \mathrm{hr}$. at $80^{\circ}$ gave a milled grain with only a slight yellow discoloration and this became hardly noticeable in the cooked grain.

An additional point in favour of treatment at the lower temperature is indicated by an observation of Yang (1949). He found that $95 \%$ of the starch of untreated rice was hydrolysed by enzymes, whereas only $88 \%$ was hydrolysed after treatment at $100^{\circ}$. Treatment at $80^{\circ}$, however, did not affect the starch in this way.

\section{SUMMARY}

I. The effects of treatments of the parboiling type on the aneurin and nicotinic acid content of whole and milled rice were investigated.

2. All treatments resulted in some loss of aneurin in the whole grain. Treatments brought about redistribution of aneurin and nicotinic acid in the grain so that a high proportion of these substances was conserved in the milled product.

3. The most satisfactory product was obtained by soaking paddy rice for $2 \mathrm{hr}$. at $80^{\circ}$.

Sincere thanks are expressed to Prof. B. S. Platt for suggesting that this problem should be investigated, and for his advice and guidance throughout the course of the work.

I would also like to thank Dr E. R. Dawson of the Research Department of the Distillers Company Ltd., who arranged for the microbiological assays to be carried our. 


\section{REFERENCES}

Aykroyd, W. R. (1932). F. Hyg., Camb., 32, 184. Bouman, J. (1948). Int. Z. Vitaminforsch. 19, 386.

Dann, W. J. \& Handler, P. (194I). F. biol. Chem. 140, 201.

Hennessy, D. J. (r947). Cold Spr. Harb. Symp. quant. Biol. 12, 86.

Hinton, J. J. C. (1948). Nature, Lond., 162, 9 13.

Hinton, J. J. C. (1948-9). Brit. Y. Nutrit. 2, 237.

Jones, J. W., Zeleny, L. \& Taylor, J. W. (1946). Circ. U.S. Dep. Agric. no. 752.

Kik, M. C. (1946). Cereal Chem. 23, 529.

Kik, M. C. \& Williams, R. R. (1945). Bull. nat. Res. Coun., Wash., no. 112.

Platt, B. S. (1939). In Nutrition in the Colonial Empire. [Cmd. 6050], p. 186. London: H.M. Stationery Office.

Potter, V. R. \& Elvehjem, C. A. (1936). F. biol. Chem. I14, 495.

Swaminathan, M. (1938). Nature, Lond., I41, 830.

Swaminathan, M. (1942). Indian F. med. Res. 30, 397.

Vitamin B Sub-committee of the Accessory Food Factors Committee of the Medical Research Council and the Lister Institute (1943). Biochem. $\mathcal{F} .37,433$.

Yang, E. F. (1949). The effect of various treatments on the digestibility of rice. Ph.D. Thesis, London. 